\title{
Mercados institucionais e a construção de territórios de paz na Colômbia
}

\author{
Mireya Eugenia Valencia Perafan \\ Universidade de Brasília - Brasília - Distrito Federal - Brasil
}

\begin{abstract}
Resumo
Este trabalho faz parte da pesquisa Transbrasil financiada pelo CNPq a qual analisou as modalidades de disseminação na América Latina e Caribe de "modelos" brasileiros de políticas públicas para a agricultura familiar e, a partir da qual, foi possível estudar diferentes políticas públicas em diferentes contextos, entre eles as políticas de compras públicas na Colômbia. Particularmente, discute-se neste texto como iniciativas pontuais de inserção a mercados e fortalecimento da segurança alimentar, geram inventivos para a reconstrução de territórios fortemente afetados pela guerra. Este é o caso particular do município de Granada na Colômbia, um município pioneiro no tema de Segurança Alimentar e Nutricional (SAN) por formular, em 2006, um acordo municipal para constituir uma mesa de diálogo em SAN (Acordo 35 de 14 de maio de 2006). Desde essa época, existiam nesta localidade ações direcionadas à compra de alimentos dos agricultores familiares (especialmente alimentos produzidos pela população vítima do conflito armado) como parte da estratégia da Agência da ONU para Refugiados/Departamento Administrativo do Sistema para Prevenção, Atenção e Recuperação de Desastres e das orientações do Plano de Desenvolvimento Municipal 20122015. Para os gestores públicos do município de Granada a compra de produtos da agricultura familiar é um caminho para dinamizar a economia local e, ao mesmo tempo, avançar na construção de um território de paz. Palavras-Chave: Granada. Compras públicas. Territórios. Difusão de Políticas Públicas.
\end{abstract}

\section{Institutional markets and Peace building territories in Colombia}

\begin{abstract}
This work makes part of the research Transbrasil financed by CNPq which analyzed different strategies of dissemination in Latin America and the Caribbean of Brazilian models of public policies for agricultural families allowing to study different public policies in differents scenes, including public procurement policies in Colombia. Particularly the discussion in this paper, the punctual markets insertion initiatives and strengthening the safety of feeding, promoting incentives for the reconstruction of territories affected by war. This is the case of Granada, a town in Colombia, pioneer in the matter of feeding strategies and nutrition (SAN), remarking that, an agreement in 2006 to stablish a workshop about SAN (agreement 35 of may the 14th of 2006). Since that year, they have strategies directed to acquire food from family farmers (specially from those who have suffered the consequences of war) making part of the strategy of the United Nations for Refugees/Administrative Department system
\end{abstract}


of prevention, Attention and disaster recovery in the Municipal Development 2012-2015. For public managers of the municipality of Granada purchase products from family farming is a way to boost the local economy and at the same time advance in the construction of a territory of peace.

Keywords: Granada. Public purchase. Territory. Public Policies Dissemination.

\section{Mercados institucionales y la construcción de territorios de paz en Colombia}

\section{Resumen}

Este trabajo hace parte de la investigación Transbrasil financiada por el CNPq la cual analizó las modalidades de diseminación en América Latina de "modelos" brasileños de políticas públicas en diferentes contextos, entre ellos las políticas de compras públicas en Colombia. Particularmente se discute en este texto cómo iniciativas puntuales de inserción a mercados y fortalecimiento de la seguridad alimentaria, generan incentivos para la reconstrucción de territorios fuertemente afectados por la guerra. Este es el caso específico del municipio de Granada en Colombia, un municipio pionero en el tema de seguridad alimentar y nutricional (SAN) por formular, em 2006, un acuerdo municipal para construir una mesa de dialogo en SAN (Acuerdo 35 de 14 de mayo de 2006). Desde esa época, existían en esa localidad acciones direccionadas a la compra de alimentos de los agricultores familiares (especialmente alimentos producidos por la población víctima del conflicto armado) como parte de la estrategia de la Agencia de la ONU para Refugiados/Departamento Administrativo del Sistema para Prevención, Atención y Recuperación de Desastres y de las orientaciones del Plano de Desarrollo Municipal 2012-2015. Para los gestores públicos del municipio de Granada la compra de productos de la agricultura familiar es un camino para dinamizar la economía local y, al mismo tiempo, avanzar en la construcción de un territorio de paz.

Palabras-Clave: Granada. Compras públicas. Territorios. Difusión de Políticas Públicas.

\section{Introdução}

O Projeto Transbrasil "Disseminação de modelos brasileiros de políticas públicas para a agricultura familiar em América Latina" foi conduzido por uma equipe interinstitucional (UNB-CDS/CEPPAC/FAV/FUP-MADER, UFRGS-PGDR, USP-EACH), e financiado pelo Conselho Nacional de Desenvolvimento Científico e Tecnológico (CNPq). Neste projeto duas políticas brasileiras foram analisadas, sendo elas as compras públicas de alimentos da agricultura familiar (Programa de Aquisição de Alimentos - PAA, e Programa Nacional de Alimentação Escolar - PNAE) e os programas de desenvolvimento territorial rural (Programa Nacional de Desenvolvimento Sustentável dos Territórios Rurais - Pronat, e Programa Territórios da Cidadania - PTC).

Em particular, em relação à política de compras públicas, analisou-se como esta foi difundida na Colômbia, Haiti e Paraguai. Os resultados dessa análise estão sendo amplamente divulgados (GRISA, VALENCIA, GIRALDO, 2018; SABOURIN, GRISA, LOPES FILHO, 2018; SABOURIN e GRISA, 2018; GRISA et al, 2018) e não serão objeto deste artigo.

Somente vale destacar que, para a difusão do Brasil para a Colômbia da política de compras públicas, Valencia, Grisa e Giraldo (2018) constataram que o processo de disseminação, ao invés de uma cópia ou transferência de política pública, é uma tradução da experiência brasileira no contexto local. Nas palavras das autoras: “As normas e as regras das compras públicas brasileiras inspiraram as mudanças 
realizadas de acordo com as possibilidades políticas e institucionais locais. Este aspecto ressalta o protagonismo e liderança das organizações públicas e privadas locais e a tradução a partir de documentos, orientações e informações consultadas na internet".

Importa neste artigo analisar, com outra lente, informações que foram recolhidas no trabalho de campo realizado no marco do projeto referido. Particularmente, interessa agora investigar como, no município de Granada (Antioquia), o programa de compras públicas e segurança alimentar favorece a reconstrução de um território fortemente afetado pela guerra. O que foi possível evidenciar é que a execução do programa de alimentação escolar de maneira descentralizada, abastecendo-se dos produtos da agricultura familiar, converte-se num dos incentivos para a reconstrução do tecido social e para a criação de oportunidades que facilitam o retorno ao município da população deslocada pela guerra.

A tenacidade dos "granadinos" e suas ações de resistência pacífica levam a abraçar propostas para a construção de mercados que implicam o fortalecimento do associativismo, a criação de marcas, o melhoramento produtivo e a articulação de vários setores em torno de uma proposta comum de consolidação do Município de Granada como um Território de Paz.

Com o propósito de entender a magnitude dos efeitos da guerra em Granada descreve-se, a seguir, dados sistematizados pelo Centro Nacional de Memória Histórica da Colômbia (CNMHC). Em um segundo momento, analisa-se o processo de desenho e implementação da política pública dos mercados institucionais e seu vínculo com o programa de alimentação escolar, para depois, na terceira parte deste texto relacionar esta ação pública com a construção do território. Encerra-se o texto com algumas considerações finais.

\section{Granada sua história de guerra, resistência e recuperação da memória}

O município de Granada fica à 79 quilômetros de distância de Medellín, capital do departamento de Antioquia na Colômbia. A relativa proximidade da segunda cidade mais competitiva da Colômbia ${ }^{1}$ (depois de Bogotá), foi um dos fatores que levou a que Granada fosse caraterizada como um município "emblemático da guerra e da paz" (CNMH,2016, p.17). Sua localização o converte em um território estratégico para a expansão militar por estar no corredor entre o Magdalena Médio² e Medellín, pontos que, a sua vez, são centrais para a economia regional (CNMH, 2016).

Segundo os dados do CNMH, entre os anos 1957 e 2012 o conflito armado na Colômbia matou cerca de 220.000 pessoas, das quais 177.000 foram civis. As proporções desta cifra nacional se repetem em Granada, onde os grupos armados demostraram toda sua sanha contra a população civil. Conforme informado no relatório Granada: memórias de guerra, resistência e reconstrução (CNMH, 2016, p. 19), não existem dados precisos sobre o número total de vítimas, mas a informação oficial disponível, com corte em março de 2016, indica 460 pessoas vítimas de

\footnotetext{
1 Segundo Índice de Competividade de Cidades de 2018 elaborado pelo Conselho Privado de Competitividade e a Universidade do Rosário de Colômbia. https:/icc.compite.com.co/

${ }^{2}$ Região central da Colômbia, nomeada assim por ter como referência o trecho sul do Rio Magdalena (principal Rio da Colômbia)
} 
assassinato seletivo, 2.992 de desaparição forçada, 59 pessoas assassinadas em 10 massacres, 98 vítimas de sequestro e 50 de violência sexual. Junto com isto, o Instituto Colombiano de Binestar Familiar (ICBF) reportou 128 crianças que ficaram órfãos.

Este histórico de guerra em Granada é protagonizado pelo enfrentamento entre quatro atores armados que disputam o controle do território e o poder sobre a população civil. Conforme o CNMH (2016), o primeiro ator a chegar é o Exército de Liberação Nacional (ELN) que se instala no município no início da década de 1980. Em 1987 chegam as frentes das Forças Revolucionarias de Colômbia (FARC) que estabelecem uma disputa com o ELN. Mais adiante, em 1998 somam-se a este fogo a terceira força bélica: os paramilitares nomeados como Autodefesas Unidas de Colômbia (AUC), que em novembro de 2000 perpetuam um massacre, assassinando indiscriminadamente 19 pessoas, e, paradoxalmente, dão como nome a um de suas frentes de "Heróis de Granada", pela "façanha" desse massacre. Ainda em 2000 (dezembro) um dos eventos que marca mais profundamente a memória da população de Granada é a tomada do centro urbano pelas FARC, arremetendo de forma brutal contra a população civil. Nessa oportunidade foi detonado um carro bomba com 400 kilogramos de dinamite, seguido de um combate que durou 18 horas e no qual foram utilizados cilindros bomba. Por fim, o quarto ator deste conflito é a quarta brigada do Exército da Colômbia que, ainda conforme o relatório do $\mathrm{CNMH}$ (2016), "fez deste município um cenário privilegiado de confrontação com a implementação da estratégia de contraguerrilha", executando cerca de dez operações militares entre 2000 e 2005 (p, 18).

Aos efeitos sobre a população civil desta "guerra de verdade", como é nomeada pelos "granadinos", soma-se a crueldade de outro tipo de ações contra os cidadãos e cidadãs deste município, como as casas bomba³, as injeções aplicadas com substancias como cianureto para assassinar de maneira seletiva, e a exposição das pessoas assassinadas como troféus (RUBIANO PINILLA, 2017; CNMH, 2016). Uma manifestação de resistência a esta história de guerra é o "Salón de Nunca Más", lugar emblemático, construído em 2009, onde reconhecem-se as vítimas e se mantem a memória coletiva para gerar consciência na população sobre o que aconteceu e que ela mesma possa evitar que aconteça novamente.

Estas manifestações de resistência começaram três dias depois do ataque cometido pelas FARC-EP em dezembro de 2000. A população mobilizou-se contra à violência que era objeto, tanto pelas AUC como pelos grupos guerrilheiros, momento capturado por uma fotografia (figura 1) que sinaliza que, "apesar da fratura do laço social (assassinatos, desaparições, e deslocamento forçado), ainda se mantem um “nós" (RUBIANO PINILLA, 2017).

\footnotetext{
${ }^{3}$ Que expluem quando alguém abre a porta.
} 


\section{Figura 1 - Granada, Território de Paz}

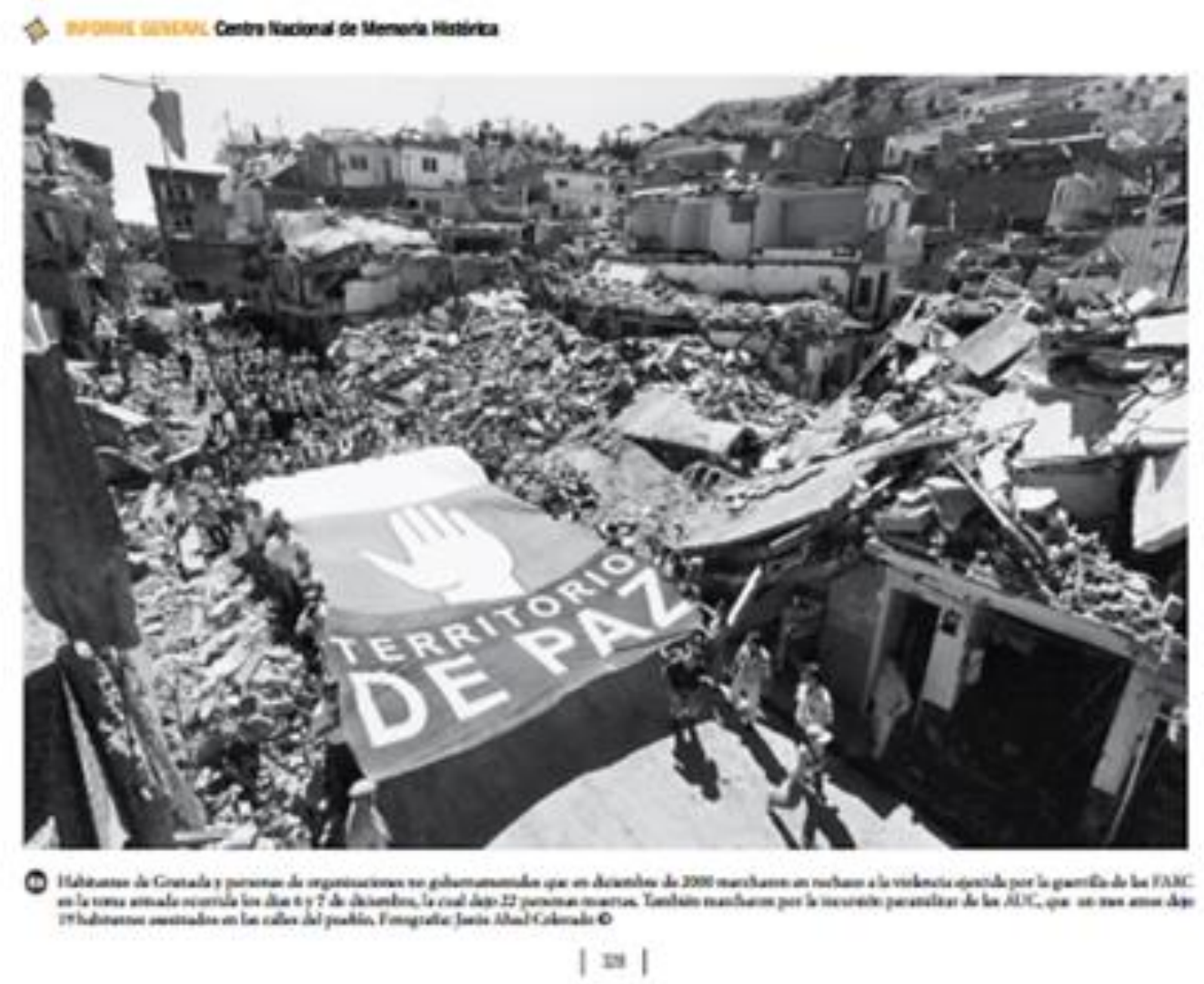

Fonte: Rubiano Pinilla (2017)

O fato dos grupos guerrilheiros (ELN e FARC-EP) serem os primeiros a adentrar nas áreas rurais de Granada, levou a considerar as famílias de agricultores camponeses como a base da guerrilha, o que, em consequência, dirigiu as ações da força pública e dos paramilitares contra essas famílias, forçando-os ao deslocamento ou assassinando-os, sob o lema "quitar-lhe a água ao pez" (CNMH, 2016). Um dos agricultores entrevistados afirmou que ele e sua família conseguiram sobreviver por uma combinação de teimosia e valentia, mas também por evitar morar na cidade (Cali ou Medellín). A esposa desse agricultor relatou que "saia da parcela com o terço na mão e não voltava a olhar para trás" "4 Uma das estratégias de sobrevivência era não ver, não denunciar, não falar.

Em questão de 10 anos a população de Granada diminuiu 50\% passando de, aproximadamente, 20.000 habitantes em 1985 para 9.859 em 2015 (CNMH, 2016). Para os gestores públicos entrevistados em junho de 2016 pela equipe do projeto Transbrasil, o ponto chave das ações que começaram a serem desenvolvidas era o "retorno" e para isto era necessário articular com todas as instituições presentes no município, descentralizar as ações, agilizar os processos e garantir a reconstrução do município desde a base. Nessa perspectiva descentralizadora, o Coordenador da Unidade Investigativa do Instituto de Estudos Sobre Paz e Desenvolvimento (Indepaz) enfatiza a importância de observar que "a defesa do território significa

\footnotetext{
${ }^{4}$ Entrevistas realizadas na zona rural de Granada em 16 de junho de 2016.
} 
defender a vida mesma e a solidariedade com as comunidades parte da base de entender e compartilhar suas lutas" 5 .

\section{Mercados Institucionais na Colômbia: Da segurança alimentar ao Fortalecimento da Agricultura Familiar}

Recentemente, depois de mais de 10 anos de vazio institucional para o desenvolvimento rural na Colômbia, observa-se a retomada de discussões sobre desenvolvimento rural, territorial e agricultura familiar por acadêmicos, organizações da sociedade civil e poder público, sendo que tal efervescência explica-se pela confluência de vários elementos. Um deles, e mais determinante, deve-se ao início das negociações pela paz entre o Governo Nacional e as Forças Armadas Revolucionárias de Colômbia (FARC) em 2012 e, neste marco, o reconhecimento do expressivo número de famílias pobres e extremadamente pobres nas áreas rurais. Este cenário permite que iniciativas que já vinham sendo desenvolvidas a partir de ações locais para fortalecimento da agricultura familiar e a segurança alimentar convertam-se em referência para possíveis alternativas de inclusão de camponeses nos mercados e, sobretudo, de fortalecimento da segurança alimentar.

Os mercados institucionais para a agricultura familiar na Colômbia é uma proposta recente. Historicamente, as ações para a segurança alimentar dentro dos programas de alimentação escolar, desenvolviam-se de maneira paralela e desconexa com os programas para o fortalecimento da agricultura familiar, os quais caracterizaram-se por "falhas históricas" de enfoque (Machado e Botelho, 2013) e pela fragmentação e debilidade da institucionalidade que as desenhavam e executavam.

Como sinalado por Valencia, Grisa e Giraldo (2018), a partir de 2010, alguns "projetos pilotos" e experiências departamentais e locais passaram a estimular a aquisição de produtos da agricultura familiar para o fornecimento na alimentação escolar. De um lado, o Instituto Colombiano de Bem Estar Familiar (ICBF) estabeleceu a obrigatoriedade de $10 \%$ ou $20 \%$ (dependendo das ações em que estão vinculados) de compras locais dos operadores; de outro lado, o Ministério da Educação estabeleceu que os operadores do Programa de Alimentação Escolar (PAE) devem aplicar, no mínimo, 20\% do total das aquisições mensais de alimentos, bens e serviços em compras locais.

Embora, a relação destas iniciativas das compras públicas com a agricultura familiar apareça nos últimos anos, os programas para a alimentação escolar na Colômbia, assim como na maioria dos países de América Latina, surgem na década dos anos 1930 (GIRALDO, 2018). Na pesquisa desenvolvida por Giraldo (2018), elabora-se uma detalhada linha do tempo sobre a trajetória da alimentação escolar na Colômbia que inicia em 1936 e chega até os tempos atuais, destacando-se três etapas que podem ser sintetizadas da seguinte maneira: i) criação-consolidação; ii) desconcentração e municipalização e iii) descentralização e compras públicas para a agricultura familiar.

Esta última etapa, que vai desde 2012 até a atualidade, está marcada pela confluência de propostas em busca do desenvolvimento rural do país. Nesse ano, e no contexto do Acordo de Paz, o governo, a Mesa da Unidade Agrária (movimentos

\footnotetext{
${ }^{5}$ Entrevista Leonardo González realizada em julho de 2018
} 
de camponeses), as FARC-EP e o Foro Agrário ${ }^{6}$ apresentaram, individualmente, propostas que convergiam na criação da Reforma Rural Integral a qual corresponde ao primeiro ponto do Acordo de Paz com o título: Hacia un Nuevo Campo Colombiano: Reforma Rural Integral. O objetivo desta reforma é a transformação estrutural da ruralidade e, particularmente, em relação às compras públicas, define uma série de estímulos à produção agropecuária e à economia solidária e cooperativa, dentre os quais encontram-se a assistência técnica, os subsídios, o crédito, a geração de renda, a formalização laboral e os mercados (Colômbia, 2016).

As mudanças institucionais realizadas para fortalecer a descentralização do programa de alimentação escolar foram, entre outros aspectos, motivadas a partir da avaliação que o Ministério de Educação (MEN) da Colômbia faz ao receber a competência de gerir o Programa que, até 2010 vinha sendo executado pelo Instituto de Bienestar Familiar Colombiano (ICBF) (GIRALDO, 2018). A centralização, baixa conexão com os territórios e a falta de acompanhamento das ações desenvolvidas destacam-se como elementos críticos na execução do PAE, levando ao MEN a formular ajustes visando, principalmente, a eficiência na utilização dos recursos. Com o objetivo de favorecer o acesso e permanência escolar de crianças e adolescentes, garantindo um complemento alimentício7, o MEN avança na conformação de um fundo comum que agrega os recursos nacionais como das entidades territoriais.

Em particular, no município de Granada, os programas de alimentação escolar vinculados às compras públicas surgem a partir de varias iniciativas. Como relatado por Valencia, Grisa e Giraldo (2018), Granada é um dos municípios pioneiros no tema de SAN ao formular, em 2006, um acordo municipal que já abordava este assunto e constituir uma mesa de diálogo em SAN (Acordo 35 de 14 de maio de 2006). Nesta localidade, executavam-se ações direcionadas à compra de alimentos dos agricultores familiares, sobretudo, as vítimas do conflito. A iniciativa visava promover a comercialização de alimentos frescos (olerícolas, ovos, frangos etc.) das Juntas de Ação Comunal (organizações da sociedade civil localizadas em cada vereda) e contribuir aos processos organizativos dos agricultores familiares. Nesse marco foi contratada pelo município a primeira organização de agricultores familiares (Associação de Pequenos Produtores Agropecuário de Granada - ADEPAG) para fornecer alimentos nas 43 instituições educativas do município. Posteriormente, e pelo resultado do pioneirismo do município sobre compras públicas, é implementado o projeto FAO-Brasil, em 2015, com o objetivo de "Promover a agricultura familiar, através da implementação dos modelos agroalimentares para o autoconsumo e a geração de renda na comercialização em articulação nos mercados institucionais locais" (GRISA, VALENCIA, GIRALDO, 2018, p 365). Entre os resultados deste programa encontram-se o incentivo à certificação dos produtos com o selo "colheitas do campo". Depois de um ano de operação, o modelo de compras públicas conseguiu atingir $17 \%$ em compras locais, mas, o operador deveria garantir produtos

\footnotetext{
${ }^{6}$ O Foro Política de Desenvolvimento Agrário Integral (Enfoque Territorial) foi realizado em Bogotá entre 17 e 19 de dezembro por encomenda da mesa de negociações entre o Governo e as FARC -EP na Havana (Cuba), com a participação de 1.314 pessoas e 522 organizações. Foram elaboradas mais de 400 propostas para o desenvolvimento agrário em atenção às comunidades rurais.

7 Para Giraldo (2018, p 55) o enfoque do PAE na Colômbia tem sido ambíguo. Nas palavras da autora: "en sus orígenes se ubicó como un proceso formativo en hábitos, en el trabajo colectivo mediante las granjas agrícolas, para posteriormente pasar a un problema nutricional y finalmente, en cabeza del MEN, transformarse en un problema de acceso y permanencia al sistema educativo.
} 
agropecuários, não agropecuários e a equipe encarregada de manipular os alimentos (FAO, 2016). Um grande resultado desta ação foi o agricultor passar de ser produtor a operador do programa.

De igual forma, este processo no município de Granada favoreceu outras reformas institucionais, dentre as quais, Grisa, Valencia e Giraldo (2018) destacam duas. A primeira delas foi a institucionalização do Comitê de Agricultura Familiar e Encadeamentos Produtivos no Conselho Municipal de Política Social - Compos, regulamentado pelo Decreto municipal no 039, de 22 de setembro de 2015. A segunda, o desenho do Plano Local de Segurança Alimentar e Nutricional que inclui a implementação de modelos agroalimentares que ligam produção às necessidades institucionais de organizações, como o ICBF, Instituto Nacional Penitenciário e Carcerário, ou programas, como o PAE.

\section{Mercados Institucionais e a Reconstrução do Território}

O programa de compras locais foi pensando pela prefeitura do município de Granada como um meio de dinamizar a economia local e, como já mencionado, criar oportunidades para o "retorno" e a reconstrução do tecido social. Granada é um município essencialmente rural cuja base produtiva é primária, com altas potencialidades como despensa alimentaria, mas também com dados históricos de pobreza e marginalização de sua população, fortemente aprofundados pela guerra. Pelos depoimentos dos atores locais é possível perceber que este tipo de ação (mercados institucionais), além de garantir mercado para os produtos dos agricultores familiares e camponeses, implementam estratégias para melhorar a produtividade, agregar valor aos produtos, favorecer a associatividade dos produtores e torna-los eles mesmos, fornecedores e operadores do programa. Com isso criam-se, também, capacidades que contribuem para a reconstrução do território na base da negociação inerente a esses novos mercados.

Como hipóteses, se poderia pensar que este caso de compras locais em Granada incentiva a confluência de uma série de atores diversos que, sob um propósito comum - a reconstrução do município - se articulam para levar adiante ações desde dentro do território. Tal vez seja muito cedo para afirmar que este tipo de articulações pode se configurar em coalizões sociais transformativas, como denominadas por Berdegué, Bebbington e Escobal (2015), mas pode se dizer que há indícios da agência de diferentes atores em torno de uma visão similar de desenvolvimento territorial. O que deveria ser investigado com maior profundidade é se, além disto, há uma ação sustentável sobre um longo período de tempo e se sua força deriva de diferentes tipos de ativos e capacidades (políticas, econômicas e culturais).

Granada é apresentada como um caso de sucesso na execução das compras públicas para a agricultura familiar pela capacidade que a gestão local teve para administrar um programa deste tipo (GRISA, VALENCIA, GIRALDO, 2018). Segundo o CNMH (2016), Granada conta com um forte tecido social, com a existência de um amplo grupo de organizações, sejam elas juntas de ação comunal, organizações religiosas, culturais e artísticas, esportivas, de vítimas, entre outras. Existem, também, dispositivos como o Comitê Interinstitucional, conformado por uma aliança 
entre instituições público-privadas que se converteu na principal estratégia social e política do conflito armado.

Este Comitê existia antes de iniciar o conflito armado e seus objetivos estavam no marco do desenvolvimento local para trabalhar projetos em diferentes áreas como a produtiva ou o saneamento básico (CNMH, 2016). Posteriormente, o Comitê focou suas ações em enfrentar os efeitos do conflito armado como "maneira de resistência cidadã" (CNMH, 2019, p. 56). Granada e sua capacidade de gestão local consegue que deste Comitê façam parte atores de diferentes escalas do território colombiano (municipal, departamental e nacional), tanto públicas, como privadas.

É possível, que a confluência de atores no município de Granada e sua capacidade para se articular, seja a evidência da "criação de espaço e oportunidade política para a formação e desenvolvimento de coalizões sociais inovadoras" (Berdegué et al, 2011). Como sugere o estudo realizado por Berdegué et al (2011), estas coalizões podem ser fortalecidas, sempre que se destinem recursos para 0 desenvolvimento territorial que cumpram, nas palavras dos autores referenciados, certas condições como: financiamento de projetos de médio prazo integrais e intersetoriais; delegação aos atores territoriais (diversos), das decisões sobre o uso desses recursos e o investimento em bens públicos que determinam as oportunidades ou restrições de desenvolvimento territorial (Berdegué et al, 2011, p.6).

As evidências identificadas no município de Granada mostram um processo de mobilização dos atores que, retomando as palavras de Pecqueur (2009, p. 12), "leva à elaboração e uma estratégia de adaptação aos limites externos, na base de uma identificação coletiva com uma cultura e um território".

$\mathrm{Na}$ base da sociologia dos mercados e de uma teoria de estudos territoriais proposta por Abramovay (2009), conflui aqui a ideia que, tanto mercados como territórios, resultam de formas específicas de interação social onde a capacidade das organizações locais de promover ligações que valorem seus conhecimentos e tradições e, particularmente em Granada, recuperem a confiança que foi desgastada pela guerra.

Desta forma, o território de Granada coloca-se perante o País com sua capacidade de se reconstruir e resistir aos violentos, desde dentro. O desafio posto, para um país como a Colômbia, é avançar em ações que favoreçam a coesão territorial a qual vai estar apoiada em formas locais de cooperação.

\section{Considerações Finais}

O estudo da política de compras públicas no município de Granada mostra que esse tipo de incentivos contribuiu com a dinamização da economia local e, por sua vez, favoreceu a coesão social e fortalecimento de capacidades para lidar com processos, não só produtivos, mas também políticos e institucionais. Constata-se que esse tipo de iniciativa tem melhor desempenho quando as capacidades dos atores territoriais Ihes permitem reagir e não se acomodar frente à guerra e seus efeitos. Em entrevista com o Presidente da ADEPAG, foi marcante escutar como ele se descobriu testemunhando um fato violento sem se importar. Existe o risco de os habitantes acomodarem-se, mas a mensagem que a experiência de Granada deixa, é que o caminho é a resistência pacífica e suas diversas formas de materializá-la. 
A análise dos processos de desenvolvimento que se implementam em localidades como Granada na Colômbia, nos ensina a levar em conta variáveis tão contundentes como o conflito armado, a qual não pode ser isolada dos processos pelos quais se criam novas estratégias como são os mercados institucionais. De fato, o longo período da guerra converte-la num costume, mas, ações de resistência como as executadas pelas comunidades em Granada e marcos institucionais como o Acordo de Paz com as FARC, trazem consigo a possibilidade de recuperar a normalidade da vida cotidiana nessa localidade com a "reconciliação lúcida das comunidades com o território que habitam" (OSPINA, 2018, p. 74).

Espera-se que esta iniciativa sobre a construção de um Território de Paz possam ser um ponto de aprendizagem para outros territórios colombianos e que o vazio institucional para o desenvolvimento rural, histórico na Colômbia, seja preenchido com ações que vajam além dos programas dispersos e de tipo compensatório que vem sendo dirigidos às populações do campo.

\section{Agradecimentos}

Os resultados apresentados neste capítulo provem do projeto TRANSBRASIL (Disseminação de modelos brasileiros de políticas públicas para a agricultura familiar na América Latina) financiado pelo CNPq Universal 2014 ( $\left.\mathrm{N}^{\circ} 443245 / 2014-2\right)$ e do projeto ECOS Sul MESAS n'U14Ho1 entre o CIRAD e a UDELAR.

\section{REFERÊNCIAS}

ABRAMOVAY, R. Para uma teoria dos estudos territoriais. In: ORTEGA, A ; ALMEIDA FILHO, N. (orgs.). Desenvolvimento Territorial, Segurança Alimentar e Economia Solidária. Campinas: Alínea, 2007.

BERDEGUÉ J.; ESCOBAL, J. e BEBBINGTON, A. Conceptualizing Spatial Diversity in Latin American Rural Development: Structures, Institutions, and Coalitions. World Development, v. 73, p 1-10, 2015.

BERDEGUÉ, J.; OSPINA, P.; FAVARETO, A.; AGUIRRE, F; CHIRIBOGA, M.; ESCOBAL, J.; FERNANANDEZ, I. GOMEZ, I.; MODREGO, F.; RAMÍREZ, E.; RAVNBORG, H.;

SCHEJTMAN; TRIVELLI, C.. Proposiciones para el desarrollo territorial. Serie Políticas para el Desarrollo Territorial. Santiago de Chile: RIMISP, 2011.

CENTRO NACIONAL DE MEMÓRIA HISTÓRICA. Granada: memorias de guerra, resistencia y reconstrucción. Bogotá, $\mathrm{CNMH}$ - Colciencias - Corporación Región, 2016.

COLÔMBIA. Acuerdo final para la terminación del conflicto y la construcción de una paz estable y duradera. Bogotá, Oficina del Alto Comisionado para la Paz Presidendia de la República, 2016

FAO; PMA. Sistematización Articulación de la Agricultura Familiar con las cadenas de abastecimiento de alimentos a los programas institucionales en Colombia. 
Bogotá: Organización de las Naciones Unidas para la Agricultura y la Alimentación (FAO), 2016.

GIRALDO, P. Alimentación escolar y compras públicas en perspectiva comparada: un análisis Colombia-Brasil. Dissertação (Mestrado em Desenvolvimento Rural) Programa de Pós-Graduação em Desenvolvimento Rural. Faculdade de Ciências Econômicas da Universidade Federal de Rio Grande do Sul, Porto Alegre, 2018.

GRISA, C; VALENCIA, M; GIRALDO, P. Transferência e tradução de políticas públicas do Brasil para a Colômbia: o caso das compras públicas da agricultura familiar. Estudos, Sociedade e Agricultura, v. 26, n.2, pp 353- 375, 2018.

GRISA C.; SABOURIN, E.; SAJAGO, D.; BALESTRO, M.; VALENCIA. M. E.; ÁVILA, M. L.; CALDAS, E.; LOPES FILHO, M. 2018. A disseminação das políticas públicas brasileiras para a agricultura familiar na América Latina em uma perspectiva comparada. In: SABOURIN, E e Grisa C. (org). A difusão de políticas brasileira para agricultura familiar na América Latina e Caribe, Porto Alegre: Ed. Escritos, 2018.

MACHADO, A.; BOTELLO, S. La Agricultura Familiar en Colombia. Serie Documentos de Trabajo $\mathrm{N}^{\circ}$ 146. Grupo de Trabajo: Desarrollo con Cohesión Territorial. Programa Cohesión Territorial para el Desarrollo. Rimisp, Santiago, Chile, 2013.

OSPINA, W. El taller el templo y el hogar. Bogotá: Penguin Random Hause Group Editorial, 2018.

PECQUEUR, B. A guinada territorial da economia global. Política \& Sociedade, n. 14, p. 79-105, 2009.

RUBIANO PIMILLA, E. Memoria, arte y duelo: el caso del Salón del Nunca Más de Granada (Antioquia, Colombia). HiSTORelo. Revista de Historia Regional y Local, v. 9, n. 18, pp 313- 343, 2017.

SABOURIN, E; GRISA C.; LOPES FILHO, M. Regional diffusion of Brazilian public policies for the strengthening of family farming. Trabalho apresentado na International Conference on Policy Diffusion and Cooperation. São Paulo, UNIFESP, 2018. Disponível em: Panel Social Policy Diffusion https://policydiffusion.com/call-forpapers-result/.

SABOURIN, E e GRISA, C. (org). A difusão de políticas brasileira para agricultura familiar na América Latina e Caribe. Porto Alegre. Ed. Escritos, 288p, 2018.

VALENCIA, M; GRISA C.; GIRALDO, P. As compras públicas da agricultura familiar na Colômbia: disseminação, tradução e institucionalização das ideias. In: SABOURIN, E e GRISA, C. (org). A difusão de políticas brasileira para agricultura familiar na América Latina e Caribe. Porto Alegre. Ed. Escritos, pp. 116 -140, 2018.

Mireya Eugenia Valencia Perafán. Professora da Universidade de Brasília na faculdade de Agronomia e Medicina Veterinária. Doutora em Ciências Sociais 
pela Universidade de Brasília e Mestre em Desenvolvimento Rural pela Pontifícia Universidade Javeriana da Colômbia.mireya_eugenia@hotmail.com

Como citar: PERAFÁN, Mireya Eugenia Valencia. Mercados institucionais e a construção de territórios de paz na Colômbia. Redes, Santa Cruz do Sul, v. 24, n. 1, p. 106-117, jan. 2019. ISSN 19826745. Disponível em: https://doi.org/10.17058/redes.v24i1.13047. 